Article

\title{
The Serine Carboxypeptidase-Like Gene SCPL41 Negatively Regulates Membrane Lipid Metabolism in Arabidopsis thaliana
}

\author{
Juan Chen ${ }^{1,2}$, Wei-qi Li ${ }^{1, *(1)}$ and Yan-xia Jia ${ }^{1, *}$ \\ 1 Germplasm Bank of Wild Species, Kunming Institute of Botany, Chinese Academy of Sciences, \\ Kunming 650201, Yunnan, China \\ 2 University of Chinese Academy of Science, Beijing 100039, China; chenjuan1@mail.kib.ac.cn \\ * Correspondence: weiqili@mail.kib.ac.cn (W.-Q.L.); jiayanxia@mail.kib.ac.cn (Y.X.J.); Tel.: +86-871-65223025
}

Received: 14 April 2020; Accepted: 26 May 2020; Published: 29 May 2020

check for updates

\begin{abstract}
The Arabidopsis has 51 proteins annotated as serine carboxypeptidase-like (SCPL) enzymes. Although biochemical and cellular characterization indicates SCPLs involved in protein turnover or processing, little is known about their roles in plant metabolism. In this study, we identified an Arabidopsis mutant, bis4 (1-butanol insensitive 4), that was insensitive to the inhibitory effect of 1-butanol on seed germination. We cloned the gene that was defective in bis4 and found that it encoded an SCPL41 protein. Transgenic Arabidopsis plants constitutively expressing SCPL41 were generated, oil body staining and lipidomic assays indicated that SCPL41-overexpressing plants showed a decrease in membrane lipid content, especially digalactosyl diglyceride (DGDG) and monogalactosyl diglyceride (MGDG) contents, while the loss of SCPL41 increased the membrane lipid levels compared with those in wild-type plants. These findings suggested that SCPL41 had acquired novel functions in membrane lipid metabolism.
\end{abstract}

Keywords: serine carboxypeptidase-like protein; membrane lipids; phosphatidic acid (PA); 1-butanol

\section{Introduction}

Serine carboxypeptidases (SCPs) and serine carboxypeptidase-like (SCPL) proteins compose a large enzyme family that functions in the hydrolysis of the C-terminal peptide bond in proteins or peptides [1-3]. SCPLs share high levels of similarity with SCPs. Arabidopsis has at least 51 members [4], while 71 SCPLs exist in the rice genome [1], indicating functional redundancy among members of the SCPL family. Several SCP/SCPL genes have been cloned and studied at the biochemical and/or molecular level from barley [5], wheat [3,6], rice [7-11], tomato [12-14], tobacco [15], Pisum sativum [16], oats [17], and Arabidopsis [18-21]. Phylogenetic analysis based on protein sequences shows that the acyltransferase of SCPLs has a single origin within the SCPL family $[4,17,22]$. Their acyltransferase function may have evolved since the divergence of higher plants from mosses, and their genes have undergone independent diversification in monocot and dicot lineages [22]. SCPL proteins in Arabidopsis are divided into two major clades. One clade consists of 21 members but only two of them are experimentally characterized as acyltransferases in plants' secondary metabolism: sinapoylglucose:malate sinapoyltransferase and sinapoylglucose:choline sinapoyltransferase [20]. Another clade comprises 25 members but their biochemical functions are not clearly defined.

Although the functions of most SCPs and SCPLs remain unknown and their known functions are still limited at the biochemical and cellular level, available evidence in plants suggests that they have various functions. For example, BRS1 (BRI1 Suppressor 1), a member of the SCP family, is a carboxypeptidase [23] working in the brassinosteroid (BR) signaling pathway [18]; SNG1 as 
acyltransferases involved in the synthesis of sinapoylmalate; glucose acyltransferase which encodes a serine carboxypeptidase-like protein functioned in glucose polyester biosynthesis, IAInos synthase as acyltransferases involved in the synthesis of indole-3-acetic (IAA) ester conjugate [12,22,24,25]; and SNG2 is involved in the biosynthesis of sinapate esters as a sinapoyltransferases [19,26,27]. Other functions include protein turnover and mobilization of storage proteins during seed germination and organ senescence [22,28]. They also have roles in signal transduction [11,18], programmed cell death [29], seed development [3,16], and secondary metabolism for herbivory defense, UV protection, and disease resistance $[19,24,27,29]$.

Major classes of cell membrane lipids include phospholipids and glycolipids. The composition of their molecules greatly affects membrane properties. They also take part in multiple cellular processes, such as signal transduction, cytoskeleton dynamics, vesicle trafficking, and secretion. One important regulatory process is that common membrane phospholipids, such as phosphatidylcholine (PC) and phosphatidylethanolamine (PE), are hydrolyzed by phospholipase D (PLD) to generate a free head-group and phosphatidic acid (PA). PA can serve as a second message to transduce environmental signaling [30-34]. PLD can mediate a specific reaction by catalyzing the transesterification of glycerophospholipids with appropriate small alcohols. For example, PLD catalyzes transphosphatidylation with 1-butanol to produce phosphatidylbutanol [35]. This reaction can block the production of PA and lead to severe physiological consequences. Treatments of seeds with 1-butanol decrease germination and result in growing defective seedlings in Arabidopsis. It is, therefore, speculated that PLD-mediated PA is crucial for germination and seedling morphogenesis by maintaining the transverse alignment of microtubules in elongating root cells [35]. However, the mechanism is not fully understood yet.

We identified an Arabidopsis mutant, bis4 (1-butanol insensitive 4), that is insensitive to the inhibitory effect of 1-butanol on seed germination. We cloned the gene that is defective in the bis 4 mutant and found that it encodes the SCPL41 protein. SCPL41 protein is a member of clade II of the SCPL family, and its biochemical functions and biological functions have not been clearly defined. We showed that SCPL41 loss-of-function mutants display PA-insensitive phenotypes in terms of their primary root growth. Transgenic Arabidopsis plants constitutively expressing SCPL41 were generated and found to have lower oil body accumulation. Lipidomic assays indicated that SCPL41-overexpressing plants showed a decrease in membrane lipid content, especially digalactosyl diglyceride (DGDG) and monogalactosyl diglyceride (MGDG) content, while the loss of SCPL41 increased the membrane lipid levels compared with those in wild-type plants. These findings suggest that SCPL41 has novel functions in membrane lipid metabolism.

\section{Results}

\subsection{Identification of the SCPL41 Protein Involved in 1-Butanol Response}

We identified a 1-butanol-insensitive mutant, named bis4 (1-butanol insensitive 4), by screening an ethyl methanesulfonate (EMS)-mutagenized plant pool (Col-0 background) for changes in the percentage of seed germination in the presence of exogenous 1-butanol. The mutation site in the mutant was detected (TAIR-PCR) in the seventh exon of AT5g42230, which encodes SCPL41 (serine carboxypeptidase-like gene 41, Figure 1A). The phenotype of bis44 (SALK_360_G01), an allelic mutant obtained from the Arabidopsis Biological Resource Center (ABRC), was comparable to that of bis4 plants. The germination rates of wild-type, bis 4 and bis 44 mutants were $17.5 \%, 74.2 \%$, and $58.0 \%$ in presence of $0.08 \%$ 1-butanol for $4 \mathrm{~d}$, respectively, which suggested germination of the bis 4 and bis 44 mutants both were insensitive to 1-butanol, compared with these processes in wild-type (Figure S1A,B). Compared with bis44 plant, bis4 plant was more insensitive to 1-butanol, which might be due to the higher inhibition of SCPL41 gene expression in bis4 than in bis44 plants. The bis4 line was chosen for subsequent experiments. We generated SCPL41-overexpressing plants containing the $35 S$ promoter fused to the SCPL41 coding region, and two overexpression lines that we named SOE-5 (SCPL41 
overexpression 5) and SOE-7 were identified. The SCPL41 expression in line 5 was higher than that in line 7, as assessed by qRT-PCR (Figure 1B). The SOE-5 line was chosen for subsequent experiments.

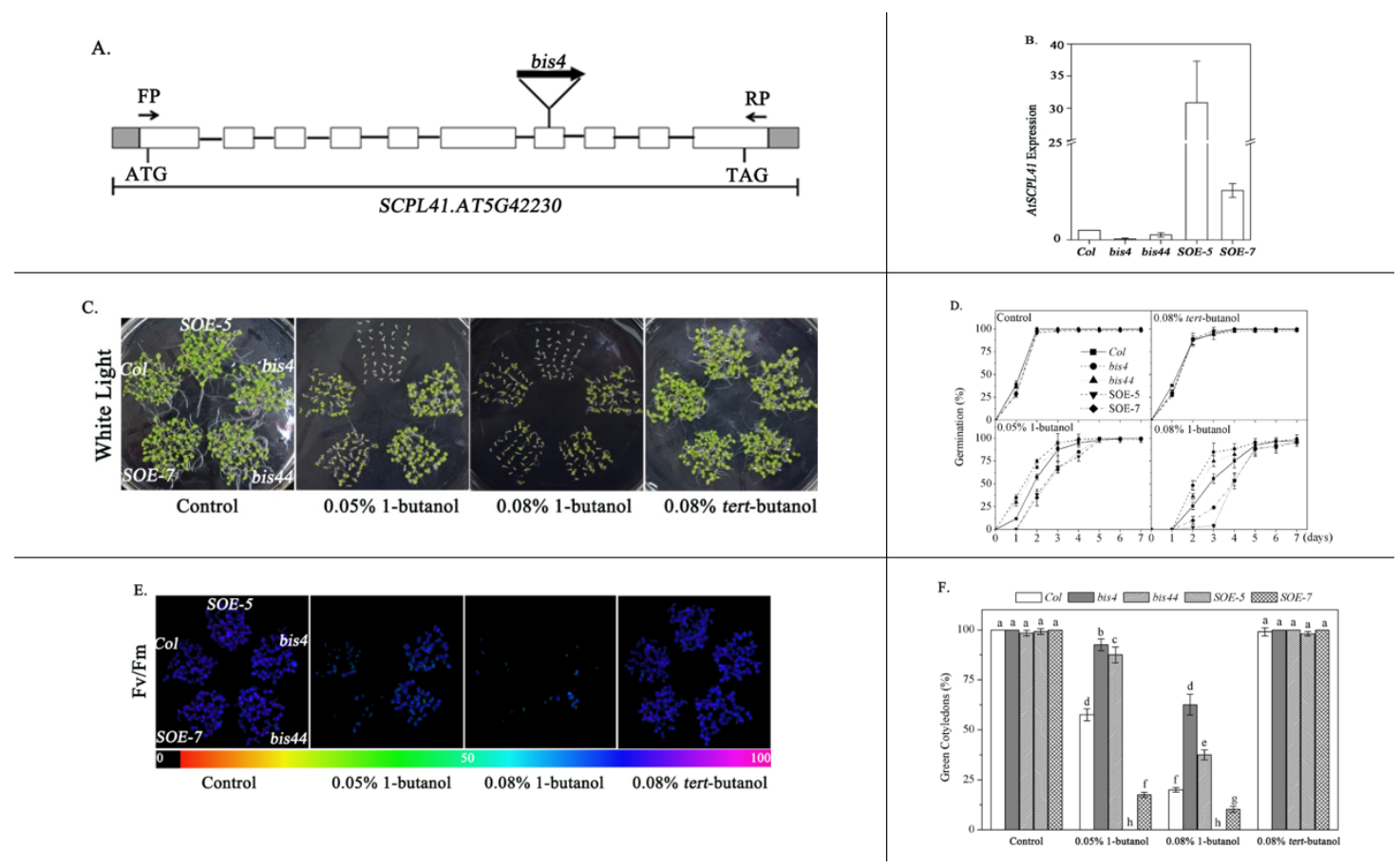

Figure 1. Seed germination and postgerminative growth of Col, bis4, bis44, SOE-5, and SOE-7 plants in response to 1-butanol. (A) Gene structure of $A T 5 g 42230$. The filled boxes indicate exons, and the lines indicate introns. The sites of insertion in the bis 4 mutant are marked. (B) Quantitative PCR analysis of SCPL41 expression in 7-d-old Col, bis4, bis44, SOE-5, and SOE-7 mutant seedlings in the absence of 1-butanol. The values are the means \pm SDs $(n=3)$. (C) Visual comparison of Col, bis4, bis44, SOE-5, and $S O E-7$ seed germination and postgerminative growth after $7 \mathrm{~d}$ in the absence or presence of $0.05 \%$ 1-butanol, $0.08 \%$ 1-butanol, or $0.08 \%$ tert-butanol. (D) Germination rate of Col wild-type as well as bis4, bis44, SOE-5, and SOE-7 plants in the absence or presence of $0.08 \%$ 1-butanol or $0.08 \%$ tert-butanol at the indicated times. (E) $F_{v} / F_{m}$ values. The color bar on the bottom indicates the $F_{v} / F_{m}$ values. (F) Green cotyledons were scored after $7 \mathrm{~d}$ of growth and represent an average of 120 seeds of at least three independent experiments \pm SDs.

The bis4, bis44, SOE-5, and SOE-7 plants were compared with the wild-type for their response to 1-butanol during seed germination. The seeds were sown onto media containing different concentrations of 1-butanol for dose-response assay, and the germination percentage was scored when their radicals obviously emerged at $2 \mathrm{~d}$ after the end of stratification. In the presence of 1-butanol, seeds without SCPL41 showed a higher seed germination percentage than did the wild-type, whereas overexpression of SCPL41 resulted in a significantly reduced seed germination percentage (Figure 1C,D). In the absence of 1-butanol, the seed germination of the different genotypes were comparable. Moreover, in the presence of tert-butanol, rather than 1-butanol, the seed germination was comparable to that of the control treatment, and no difference was detected among Col, bis4, bis44, SOE-5, and SOE-7 plants (Figure 1C,D).

The Col, bis4, bis44, SOE-5, and SOE-7 plants were also examined for their response to 1-butanol during the postgerminative growth stage. In the absence of 1-butanol or in the presence of tert-butanol, cotyledon greening and photochemical quantum efficiency of the photosystem II (PS II) reaction center $\left(\mathrm{F}_{\mathrm{v}} / \mathrm{F}_{\mathrm{m}}\right)$ of the three genotypes were comparable (Figure 1E). In the presence of 0.08\% 1-butanol, the cotyledon greening and $\mathrm{F}_{\mathrm{v}} / \mathrm{F}_{\mathrm{m}}$ of bis 4 and bis 44 seedlings were much higher than those of wild-type. In contrast, the cotyledon greening and $\mathrm{F}_{\mathrm{v}} / \mathrm{F}_{\mathrm{m}}$ of $S O E-5$ and $S O E-7$ were lower than those of the wild-type (Figure 1E,F). In addition, the tested SCPL41-overexpression lines revealed that line 5 
was more sensitive to 1-butanol than line 7. Given that SCPL41 expression levels in line 5 were higher than those in line 7 (Figure 1B), our results suggested that the 1-butanol hypersensitivity in these SCPL41-overexpression lines is correlated with their SCPL41 expression levels. Taken together, these results suggested that SCPL41 acted as a positive regulator of 1-butanol response during germination and postgerminative growth.

To verify whether the different responses of SCPL41 expression lines to 1-butanol are related to the altered lipid metabolism in these plants, we first compared the total lipid levels in the developing cotyledonary leaves of Col, bis4, SOE-5, and SOE-7 plants by Nile red staining [36]. The higher the fluorescence intensity, the higher the total lipid content. Significantly lower lipid accumulation was observed in the cotyledons of SOE-5 and SOE-7 plants than in those of wild-type plants; however, the total lipid accumulation in the bis 4 mutant was comparable to that in the wild-type plants (Figure 2A,B). These results suggested that SCPL41 might be involved in lipid metabolism.
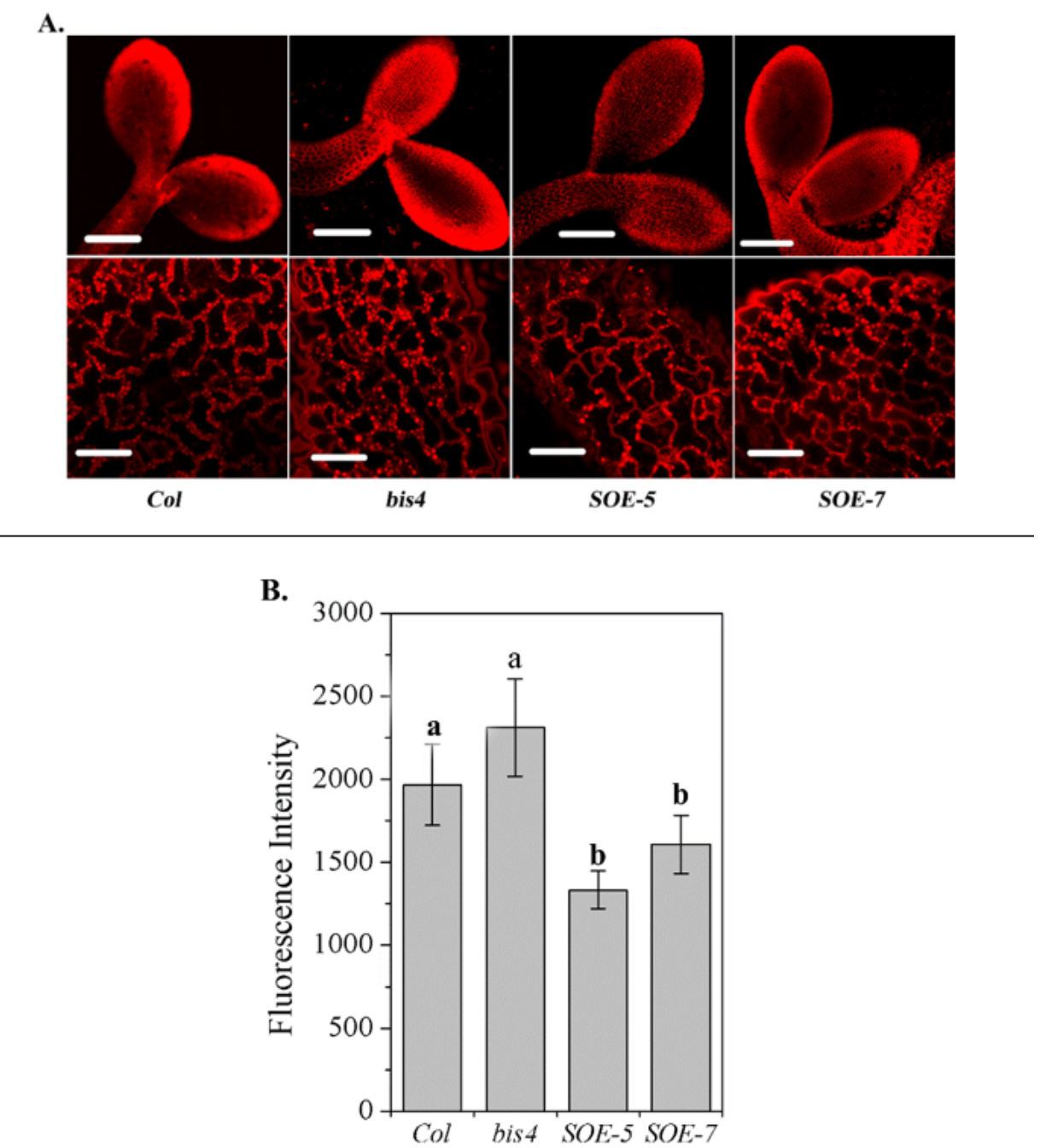

Figure 2. Level of total lipid accumulation in the cotyledonary leaves of Col, bis4, SOE-5, and SOE-7 plants. (A) Representative images of lipid accumulation in 2-d-old cotyledonary leaves of Col, bis4 mutant, $S O E-5$, and SOE-7 plants after staining the seedlings with Nile red. The top panel images were captured at $10 \times$ magnification with an Olympus FV 1000 system. Bars $=200 \mu \mathrm{m}$; the bottom panel images were captured at $60 \times$ magnification with an Olympus FV 1000 system. Bars $=30 \mu \mathrm{m}$. (B) Fluorescence intensity. The average fluorescence intensity of the whole cotyledon was calculated. The higher the fluorescence intensity, the higher the total lipid content. 


\subsection{SCPL41 Had Different Effects on The Content and Composition of Lipids}

Since the above results suggested that SCPL41 was involved in lipid metabolism, we then comparably profiled the membrane lipids in Col, bis4, and SOE-5 plants, and identified $>110$ molecular species of polar glycerolipids, including six head-group classes of phospholipids, PC, PE, PA, phosphatidylinositol (PI), phosphatidylserine (PS), and phosphatidylglycerol (PG), and two head-group classes of galactolipids, MGDG and DGDG (Table 1). Each molecular species was identified in terms of the total numbers of acyl carbon atoms and double bonds [37].

Table 1. Total lipids in Col, bis4, and SOE-5 plants.

\begin{tabular}{|c|c|c|c|c|c|}
\hline \multirow{2}{*}{ Lipid Classes } & \multicolumn{3}{|c|}{ Lipids/Dry Weight (nmol/mg) } & \multicolumn{2}{|c|}{ Ratio } \\
\hline & Col & bis4 & SOE-5 & bis4/Col & SOE-5/Col \\
\hline PG & $10.88 \pm 0.45^{b}$ & $12.28 \pm 0.39^{\mathrm{a}}$ & $8.44 \pm 0.79^{c}$ & 112.84 & 77.57 \\
\hline PC & $35.14 \pm 2.21^{b}$ & $38.70 \pm 2.44^{a}$ & $31.43 \pm 0.45^{c}$ & 110.13 & 89.43 \\
\hline PE & $21.02 \pm 0.95^{b}$ & $23.85 \pm 1.33^{\mathrm{a}}$ & $17.41 \pm 1.72^{\mathrm{c}}$ & 113.46 & 82.87 \\
\hline PI & $5.44 \pm 0.32^{\mathrm{a}}$ & $5.79 \pm 0.69^{a}$ & $5.53 \pm 0.17^{a}$ & - & - \\
\hline PA & $1.55 \pm 0.25^{\mathrm{a}}$ & $1.74 \pm 0.34^{\mathrm{a}}$ & $1.81 \pm 0.15^{\mathrm{a}}$ & - & - \\
\hline PS & $0.88 \pm 0.06^{\mathrm{a}}$ & $1.02 \pm 0.25^{\mathrm{a}}$ & $0.80 \pm 0.17^{\mathrm{a}}$ & - & - \\
\hline MGDG & $44.33 \pm 2.11^{b}$ & $49.43 \pm 2.76^{\mathrm{a}}$ & $33.75 \pm 4.54^{\mathrm{c}}$ & 111.50 & 76.15 \\
\hline DGDG & $11.42 \pm 0.80^{\mathrm{a}}$ & $12.09 \pm 1.08^{a}$ & $9.20 \pm 1.09^{b}$ & - & 80.58 \\
\hline \multicolumn{6}{|c|}{ Total lipids/dry weight (nmol/mg) } \\
\hline Total lipids & $127.26 \pm 2.37^{b}$ & $146.89 \pm 8.11^{a}$ & $108.97 \pm 7.65^{c}$ & 115.43 & 83.02 \\
\hline
\end{tabular}

$\mathrm{Col}, \mathrm{bis} 4$ and SOE-5 plants with different letters $\mathrm{a}, \mathrm{b}$ and $\mathrm{c}$ in the same row indicate significantly differences. $(P<0.05)$.

The values are the means \pm SDs $(n=5)$.

As an overview, the profile of most lipid species in terms of their absolute level (nmol/mg dry weight, Figure 3, left panel) and their relative content (mol \% of total lipids, Figure 3, right panel) was different among wild-type, bis4, and SOE-5 Arabidopsis. Compared to wild-type, the absolute levels of most lipids were lower in the SOE-5 plants than in the wild-type Arabidopsis but higher in the bis4 plants (Figure 3). Compared to these in wild-type Arabidopsis, the composition of most lipid species in the SOE-5 plants increased, except for MGDG molecules, while a few lipid species changed in bis4 plants. These results suggested that the change in SCPL41 expression dramatically affected lipid degradation and lipid composition, albeit in different ways.

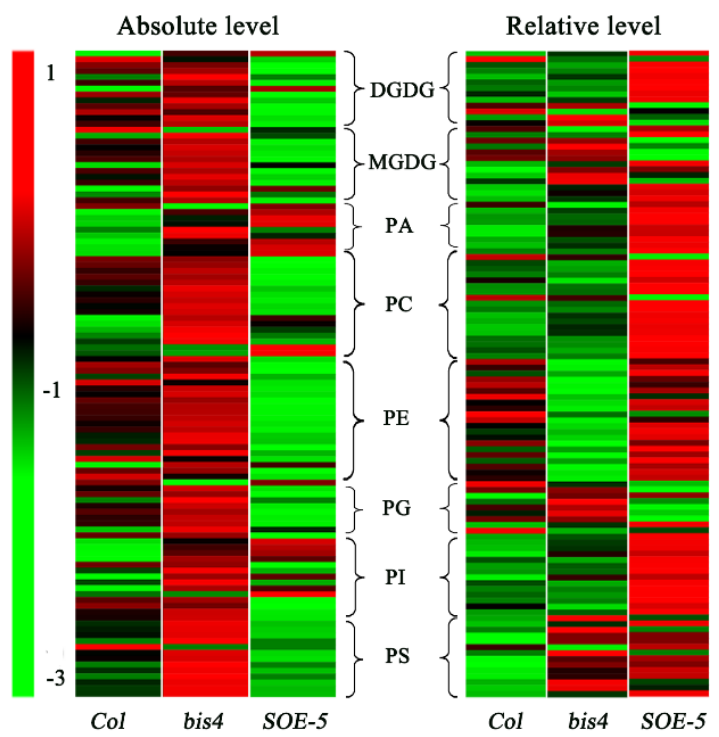

Figure 3. Heat map of lipid molecular species in Col, bis4, and SOE-5 plants. Each color bar in the column represents lipid molecular species in the indicated plant. The color of each bar represents the relative change from the median of each lipid species $(n=5)$. 
2.3. Overexpression of SCPL41 Decreased the Membrane Lipid Content, but Loss of SCPL41 Increased the Membrane Lipid Content

Compared to that in the wild-type, the number of total lipids in SOE-5 plants decreased to $83.02 \%$, while it increased to $111.91 \%$ in bis 4 plants (Table 1). The most important changes concerned the two galactolipids. The level of MGDG in the SOE-5 plants decreased to $76.15 \%$, and the level of DGDG decreased to $80.58 \%$. The level of PG decreased to $77.57 \%$. The levels of PC and PE were also significantly higher in wild-type plants than in SOE-5 plants, while no differences in the levels of PI, PA, or PS were detected between wild-type and SOE-5 plants. However, the deletion of SCPL41 increased the content of total lipids (from $127.26 \mathrm{nmol} / \mathrm{mg}$ to $146.89 \mathrm{nmol} / \mathrm{mg}$, Table 1). Compared to those in the wild-type, the levels of PG, PC, PE, and MGDG in the bis4 plants increased obviously (Table 1). MGDG 34:6 and 36:6 molecular species as well as the DGDG 36:6 in SOE-5 plants were much lower than those in wild-type plants (Figure 4). The levels of PG 34:2, 34:3, and 34:4; PC 34:5 and 34:6; and PE 34:2, 34:3, $36: 4$, and 36:5 were also lower in the SOE-5 plants than in the wild-type plants. The levels of PC $36: 4$ and 36:5, PE 34:2 and 34:3 and PG 34:4 increased because of the deletion of SCPL41 in bis4 plants. The content of other lipid molecular species showed no clear difference compared with those in wild-type plants (Figure 4). These results indicated that SCPL41 had a negative correlation between SCPL41 gene expression and membrane lipid content, further confirming that SCPL41 regulates membrane lipid metabolism.

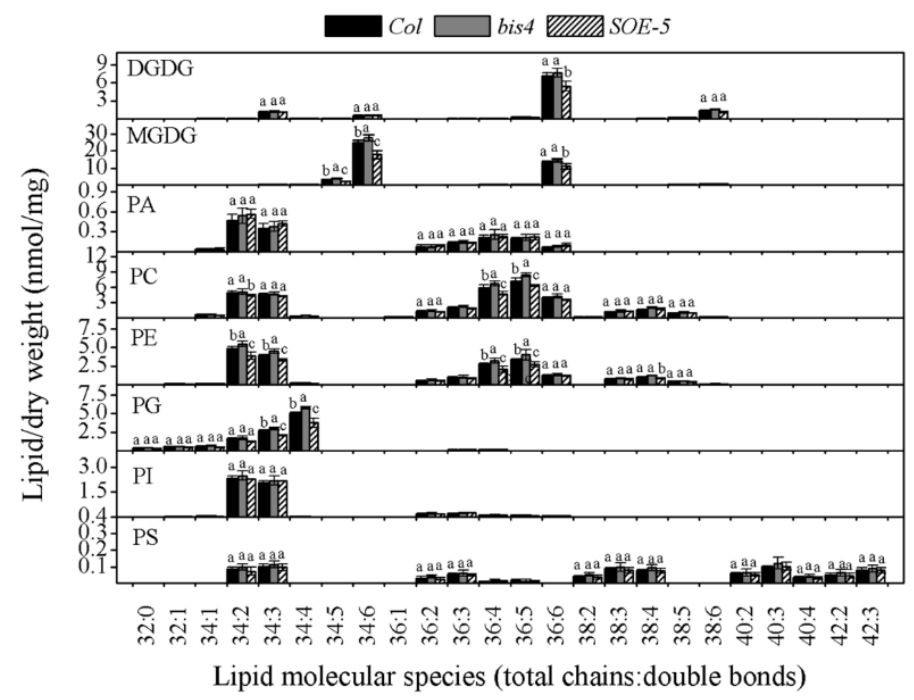

Figure 4. Changes in the molecular species of lipids in Col, bis4, and SOE-5 plants. The values are the means \pm SDs $(n=4$ or 5$)$. Bars for the same lipid class with different letters indicate that the values were significantly different $(P<0.05)$.

\subsection{SCPL41 Had No Effect on the Composition of Lipid Classes}

For the analysis of the relative contents of membrane lipids (mol \% total lipids), we only found MGDG and PG percentages slightly lower and PI and PA percentage slightly higher in SOE-5 plants than that in wild-type (Table 2). The compositions of the lipid molecular species were basically the same among Col, bis4, and SOE-5 plants (Figure S2). The ratio of galactolipids/phospholipids was 0.74 and 0.65 in wild-type and $S O E-5$ plants, respectively, which might have resulted from the relatively low content of MGDG in the SOE-5 plants (Table 2). 
Table 2. Membrane lipid composition in each head-group class and lipid ratio in Col, bis4, and SOE-5 plants.

\begin{tabular}{cccc}
\hline \multirow{2}{*}{ Lipid Classes } & \multicolumn{3}{c}{ Lipid (mol \% of Total Lipids) } \\
\cline { 2 - 4 } & Col & bis4 & $S O E-5$ \\
\hline PG & $8.41 \pm 0.31^{\mathrm{a}}$ & $8.61 \pm 0.38^{\mathrm{a}}$ & $7.85 \pm 0.26^{\mathrm{b}}$ \\
PC & $26.72 \pm 0.74^{\mathrm{a}}$ & $26.79 \pm 0.99^{\mathrm{a}}$ & $28.91 \pm 2.12^{\mathrm{a}}$ \\
PE & $16.01 \pm 0.42^{\mathrm{a}}$ & $14.47 \pm 2.72^{\mathrm{a}}$ & $15.98 \pm 0.99^{\mathrm{a}}$ \\
PI & $4.14 \pm 0.13^{\mathrm{b}}$ & $4.24 \pm 0.34^{\mathrm{ab}}$ & $5.01 \pm 0.41^{\mathrm{a}}$ \\
PA & $1.18 \pm 0.19^{\mathrm{b}}$ & $1.28 \pm 0.23^{\mathrm{b}}$ & $1.66 \pm 0.11^{\mathrm{a}}$ \\
PS & $0.67 \pm 0.04^{\mathrm{a}}$ & $0.74 \pm 0.11^{\mathrm{a}}$ & $0.73 \pm 0.14^{\mathrm{a}}$ \\
MGDG & $33.72 \pm 0.36^{\mathrm{a}}$ & $34.55 \pm 1.25^{\mathrm{a}}$ & $30.81 \pm 2.14^{\mathrm{b}}$ \\
DGDG & $8.70 \pm 0.31^{\mathrm{a}}$ & $8.88 \pm 0.31^{\mathrm{a}}$ & $8.42 \pm 0.43^{\mathrm{a}}$ \\
\hline & & Lipid ratio & \\
PC/PE & $1.67 \pm 0.06^{\mathrm{a}}$ & $1.93 \pm 0.53^{\mathrm{a}}$ & $1.82 \pm 0.18^{\mathrm{a}}$ \\
DGDG/MGDG & $0.26 \pm 0.01^{\mathrm{a}}$ & $0.26 \pm 0.01^{\mathrm{a}}$ & $0.27 \pm 0.01^{\mathrm{a}}$ \\
Galactolipids/Phospholipids & $0.74 \pm 0.02^{\mathrm{a}}$ & $0.77 \pm 0.04^{\mathrm{a}}$ & $0.65 \pm 0.07^{\mathrm{b}}$ \\
\hline
\end{tabular}

Col, bis 4 and SOE-5 plants with different letters $\mathrm{a}, \mathrm{b}$ and $\mathrm{c}$ in the same row indicate significantly differences. $(P<0.05)$. The values are the means \pm SDs $(n=4$ or 5$)$.

Both PC and DGDG have relatively large head-groups, in terms of chemical structure, and tend to form a bilayer lipid phase. In contrast, PE and MGDG have small head-groups involved in the formation of a nonbilayer lipid phase. The molar PC/PE and DGDG/MGDG ratios are positively related to membrane stability $[37,38]$, we compared these ratios in bis 4 and SOE-5 plants with that in wild-type plants (Table 2) and found no difference. The degree of unsaturation of membrane lipids significantly impacts the fluidity of the membranes. It is indicated by a double bond index (DBI), an average number of double molecular species. The DBI of each lipid remained unchanged under different levels of SCPL41 expression (Table 3). These results suggested that SCPL41 might have no effect on the lipid composition, membrane stabilization, or fluidity.

Table 3. Double bond index (DBI) of each lipid class.

\begin{tabular}{cccc}
\hline \multirow{2}{*}{ Lipid Class } & \multicolumn{3}{c}{ DBI (Double Bond Index) } \\
\cline { 2 - 4 } & \multicolumn{1}{c}{ Col } & bis4 & SOE-5 \\
\hline DGDG & $6.48 \pm 0.02^{\mathrm{b}}$ & $6.51 \pm 0.01^{\mathrm{a}}$ & $6.39 \pm 0.04^{\mathrm{c}}$ \\
MGDG & $6.84 \pm 0.01^{\mathrm{a}}$ & $6.84 \pm 0.01^{\mathrm{a}}$ & $6.83 \pm 0.01^{\mathrm{a}}$ \\
PG & $2.98 \pm 0.04^{\mathrm{a}}$ & $2.97 \pm 0.04^{\mathrm{a}}$ & $2.94 \pm 0.07^{\mathrm{a}}$ \\
PC & $3.81 \pm 0.02^{\mathrm{a}}$ & $3.82 \pm 0.02^{\mathrm{a}}$ & $3.80 \pm 0.01^{\mathrm{a}}$ \\
PE & $3.43 \pm 0.02^{\mathrm{a}}$ & $3.44 \pm 0.02^{\mathrm{a}}$ & $3.43 \pm 0.02^{\mathrm{a}}$ \\
PI & $2.59 \pm 0.01^{\mathrm{a}}$ & $2.58 \pm 0.01^{\mathrm{a}}$ & $2.58 \pm 0.01^{\mathrm{a}}$ \\
PS & $2.70 \pm 0.02^{\mathrm{a}}$ & $2.69 \pm 0.05^{\mathrm{a}}$ & $2.75 \pm 0.04^{\mathrm{a}}$ \\
PA & $3.06 \pm 0.02^{\mathrm{a}}$ & $3.11 \pm 0.06^{\mathrm{a}}$ & $3.10 \pm 0.09^{\mathrm{a}}$ \\
\hline
\end{tabular}

Col, bis 4 and $S O \overline{E-5}$ plants with different letters $\mathrm{a}, \mathrm{b}$ and $\mathrm{c}$ in the same row indicate significantly differences. $(P<0.05)$. The values are the means \pm SDs $(n=4$ or 5$)$.

\subsection{SCPL41 Had No Effect on the PA content, But Might be Involved in PA Signaling}

PA is the product of PLD-mediated phospholipid hydrolysis and plays an important role in many physiological processes [39-41]. One process at the seedling stage is that exogenous application inhibits primary root length [42]. We examined the absolute level of PA and the PLD substrate, such as PC and $\mathrm{PE}$, in Col, bis4, and SOE-5 plants, and no significant differences in PA levels were detected (Table 1). This suggests that SCPL41 had no effect on the PA content. However, the exogenous application of PA showed that the inhibition of primary root length is suppressed in bis 4 mutants. The SOE-5 plants had comparable root length to that of wild-type plants. No obvious difference was detected in the root 
growth of any of the plants when exposed to exogenous PC (Figure 5). These results suggested that SCPL41 might play a positive role in PA signaling.
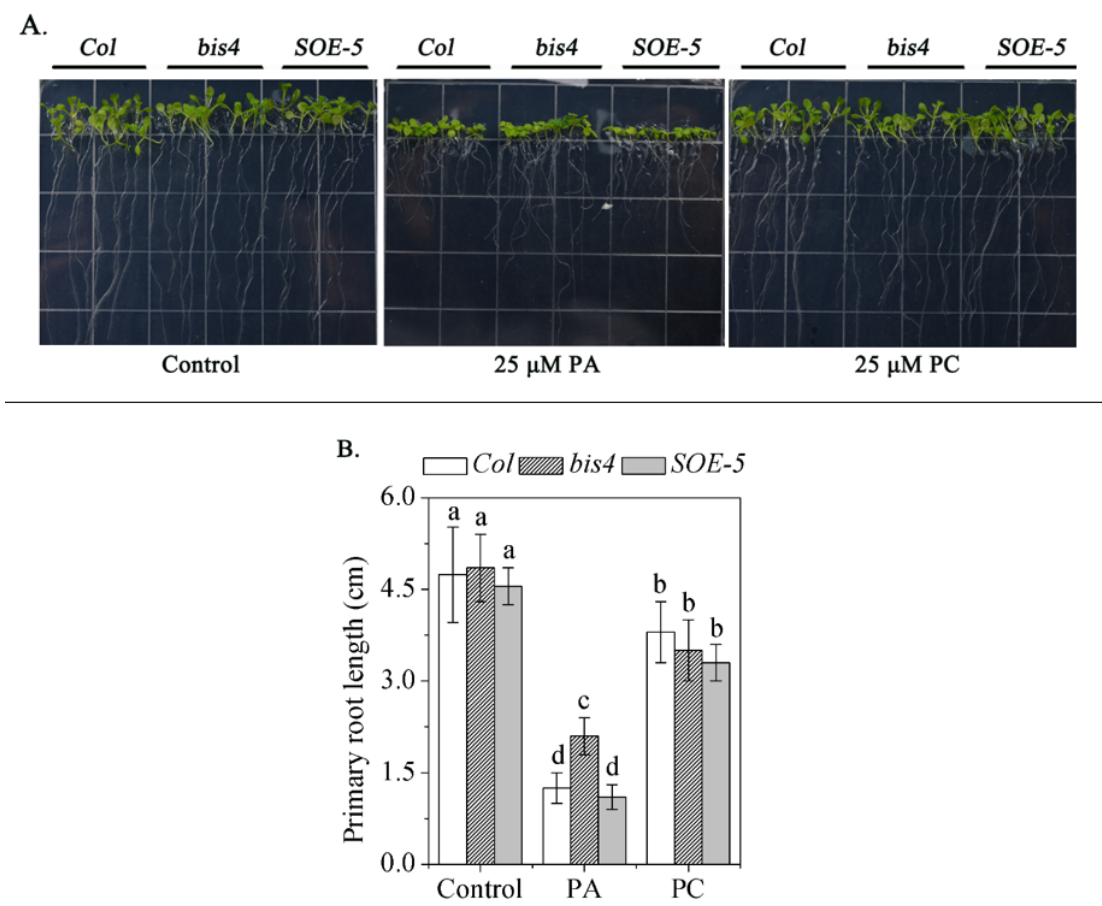

Figure 5. Primary root growth phenotype of Col, bis4, and SOE-5 plants. (A) Seeds were germinated on MS media for $3 \mathrm{~d}$, after which they were transferred to $25 \mu \mathrm{M}$ phosphatidylcholine (PC) or phosphatidic acid (PA). (B) The length of the primary roots of each genotype plant was averaged after $6 \mathrm{~d}$ of vertical growth. Bars with different letters indicate that the value was significantly different $(P<0.05)$.

\section{Discussion}

SCP and SCPL family members are expressed in all major tissue types [4] and take part in wide biochemical and cellular processes $[16,17,19,24,43,44]$ in plants, including secondary metabolite biosynthesis, herbicide conjugation, and germination-associated protein degradation in seed reserves. In the present study, we investigate the role of SCPL41 in lipid metabolism and signaling during the germination and postgerminative growth in Arabidopsis. Deletion and overexpression of SCPL41 confer seeds resistant and sensitive to the inhibitory effect of 1-butanol on seed germination, respectively (Figure 1). The known suppression of 1-butanol on PLD-mediated PA formation led us to investigate the role of SCPL41 in lipid metabolism. We indeed observed lipids accumulated significantly lower in cotyledonary leaves of SCPL41 overexpression plants (Figure 2). Lipid profiling further confirmed that deletion and overexpression of SCPL41 significantly increase and decrease the content of membrane glycerolipids, respectively (Figure 3 and Table 1), while basically maintaining their composition, DBI, and PC/PE and DGDG/MGDG ratios. The PA contents are not affected by SCPL41 but the inhibitory effect on primary root length is attenuated in the absence of SCPL41 (Figure 5). Our results demonstrate that SCPL41 positively regulates membrane lipid metabolism and suggests that it has a positive role in PA signaling.

SCPL41 was expressed ubiquitously at relatively high levels in flowers but at relatively low levels in seedlings [4]. During the identification and growth of all plant genotypes, no morphological or developmental issue changes were observed, suggesting that SCPL41 does not have effects on plant growth and development under normal conditions. The increased expression of SCPL41 caused a large decrease in the contents of PG, MGDG, and DGDG. They are plastidic lipids, the most abundant in leaves [45], and have a direct role in photosynthesis [38]. However, overexpression of SCPL41 did not affect the lipid composition or the stability of the chloroplast membrane, as reflected by the 
DGDG/MGDG ratio (Table 2), which also contributed to maintaining photosynthetic activity [46]. This is consistent with the normal photosynthesis activity in SOE-5 plants, as measured by $\mathrm{F}_{\mathrm{v}} / \mathrm{F}_{\mathrm{m}}$ (Figure 1E).

SCPLs have been identified by various genetic approaches. Forward genetic screens found mutant plants without specific acylated compounds and led to the identification of SNG1 [24] and SNG2 [20] in Arabidopsis, and AsSCPL1 in oat [17]. Activity-guided purification and protein sequencing led to the identification of the tomato GAC enzyme [12]. In our case, SCPL41 in Arabidopsis was identified by screening an EMS mutagenized pool for changes in seed germination in the presence of exogenous 1-butanol (Figure S1). 1-Butanol is involved in the transphosphatidylation reaction as a substrate to produce phosphatidyl alcohol or PA [47]. Thus, we proposed that SCPL41 might be required for phospholipid metabolism or PA-dependent signaling in Arabidopsis. Overexpression of SCPL41 induced a marked decrease in contents of PC, PE, and PG, which are substrates of phospholipid hydrolysis via PLD, and the deletion of SCPL41 increased the PC, PE, and PG contents to some extent. The PI and PS contents were not affected when the expression of SCPL41 changed, which might be because the content was too low to reflect the difference. The SCPL enzymes identified so far are involved in the biosynthesis of glucose polyesters [12], sinapate esters [19,48], anthocyanins, avenacins, tannins [17], and indole-3-acetic acid (IAA) ester conjugates [25,49]. To the best of our knowledge, SCPL41 is the first member of the SCPL family functioning in cell membrane lipid metabolism.

Previous reports have demonstrated that 1-butanol inhibited seed germination and that 1-butanol blocked PLD-mediated PA produce. It was, therefore, assumed that the 1-butanol inhibition of germination resulted from the absence of PLD-dependent PA [50-52]. However, our evidence showed that the insensitivity or hypersensitive of germination to 1-butanol was correlated to the expression of SCPL41 but the expression of SCPL41 was not correlated to PA content (Figure 1 and Table 1). Thus, the previous assumption may be incorrect. However, more evidence is needed to prove our speculation. Biochemical characterization of the SCPL41 protein and functional studies of the SCPL41 gene with knockout/knockdown mutants and/or overexpression in transgenic plants will provide new insights into the biological function and mechanism of SCPL41 in response to 1-butanol in Arabidopsis.

\section{Material and Methods}

\subsection{Plant Materials and Growth Conditions}

Arabidopsis thaliana ecotype Columbia (Col-0) was used in the present study. Surface sterilization of all genotype seeds as conducted with $75 \%$ ethanol for 2 min followed by $5 \% \mathrm{NaClO}$ for $2 \mathrm{~min}$ and then sterile water rinse three times. The sterilized seeds on MS media with $0.1 \%$ agarose were pretreated at $4{ }^{\circ} \mathrm{C}$ in darkness for $2 \mathrm{~d}$ and then germinated in a growth chamber with conditions of $22{ }^{\circ} \mathrm{C}, 16-\mathrm{h}$ light/ 8 -h dark photoperiod, and $120 \mu \mathrm{mol} \mathrm{m}{ }^{-2} \mathrm{~s}^{-1}$ light intensity.

\subsection{Phenotype Analysis}

Seeds of different genotypes were collected from the plants grown in the same conditions at the same time. For phenotype examination, seeds and seedlings (postgerminative growth) of each genotype were germinated and grown side by side on the same plate containing MS medium with different concentrations of 1-butanol and tert-butanol as indicated. The germination rate was measured at the percentage of seed with radicle emergence at the indicated times. The percentage of cotyledon greening was recorded after $7 \mathrm{~d}$ germination when cotyledons fully expand and turn green. The effect of 1-butanol on cotyledon greening was also quantified by chlorophyll fluorescence of the seedlings (imaging chlorophyll fluorometer, MAXI-Imaging Pulse-Amplitude, Walz/Germany) $[53,54]$ as follows: after dark-adapted for 20 minutes, the maximal quantum yield of photosystem II (PS II) photochemistry $\left(\mathrm{F}_{\mathrm{v}} / \mathrm{F}_{\mathrm{m}}\right)$ was measured by the initial fluorescence level $\left(\mathrm{F}_{0}\right)$ and the maximal fluorescence level $\left(\mathrm{F}_{\mathrm{m}}\right)$ with the equation of $F_{v} / F_{m}=\left(F_{m}-F_{0}\right) / F_{m}$. 


\subsection{Transgenic Plants}

The coding region of SCPL41 was cloned into a pEGAD-GFP binary vector driven by the cauliflower mosaic virus $35 \mathrm{~S}$ promoter. SCPL41-overexpressing transgenic plants (in the Col-0 background) were generated using Agrobacterium-mediated floral transformation. RT-PCR and resistance screening with glufosinate-ammonium were used to detect the abundance of the transgene transcripts. The homozygous T3 seeds of the transgenic plants were used for analysis.

\subsection{Nile Red Staining}

To visually detect neutral lipids, two-day-old seedlings of wild-type, bis4, SOE-5, and SOE-7 were infiltrated with an aqueous solution of Nile red (Sigma) $[36,55]$. The seedlings were placed in sterile water, cotyledonary leaves were imaged at $10 \times$ and $60 \times$ objective with an Olympus FV 1000 system equipped with argon as an excitation source. Fluorescence was detected at $515 \mathrm{~nm}$ and collected with a 539-653 $\mathrm{nm}$ filter $(n=12$ per replicate).

\subsection{Lipid Analysis and Data Processing}

The 7-day-old seedlings were analyzed by electrospray ionization tandem mass spectrometry (ESI-MS/MS) [37] to detect the lipids and the data was processed by the methods previously reported [54]. Lipids in each class were quantified by comparing them with two internal standards and were recorded as nanomoles per milligram of plant dry weight. We analyzed five replicates of each plant species at each sampling time. Paired values were subjected to a $t$-test to determine statistical significance.

The double bond index (DBI) of acyl chains in a given lipid class was calculated using the equation: Double Bond Index $(\mathrm{DBI})=\left[\sum(\mathrm{N} \times \mathrm{mol} \%\right.$ fatty acid $\left.]\right) / 100$, where $\mathrm{N}$ is the total number of double bonds in each lipid molecule [56].

\subsection{RNA Isolation and Quantitative PCR}

Total RNA was extracted using the RNeasy Plant Mini Kit (Qiagen, QIAGEN N.V. Corporate, Germany) and reverse-transcribed via the reverse transcriptase (Invitrogen, Invitrogen Corporation, United States) according to the manufacturer's instructions. A total of $50 \mathrm{ng}$ cDNA was used for quantitative PCR in each reaction with SYBR Green PCR Master Mix (Takara, TaKaRa Biotechnology (Dalian) Co.,Ltd., Japan), and then detected by using ABI real-time PCR detection system (Quantstudio 7, QuantStudio 7, Applied Biosystems, United States). Relative amounts of SCPL41 transcripts were calculated by the comparative cycle threshold method normalized to ACTIN2 expression from the same sample. Values were determined from three replicates.

Supplementary Materials: The following are available online at http://www.mdpi.com/2223-7747/9/6/696/s1, Figure S1. SCPL41 is required for normal seed germination in response to 1-butanol. (A) Visual comparison of $\mathrm{Col}$, bis4, and bis 44 seed germination and postgerminative growth after $6 \mathrm{~d}$ in the absence or presence of $0.05 \%$ 1-butanol, $0.08 \%$ 1-butanol, or $0.08 \%$ tert-butanol. Mean \pm SD values were determined from three replicates $(n=120)$. (B) Germination rate of $\mathrm{Col}$ wild type, bis 4 and bis 44 over $6 \mathrm{~d}$ in the absence or presence of $0.05 \%$ 1-butanol, $0.08 \%$ 1-butanol, or $0.08 \%$ tert-butanol at indicated times. Figure S2. Lipid composition within each head-group class in Col, bis 4 and SOE-5 plants. The values are the means \pm SDs $(n=4$ or 5$)$.

Author Contributions: Investigation, J.C., and Y.-X.J.; conceptualization, Y.-X.J.; writing, Y.-X.J. and W.-Q.L.; funding acquisition, Y.-X.J.; supervision, W.-Q.L. All authors have read and agreed to the published version of the manuscript.

Funding: This research was supported by grants from the National Natural Science Foundation of China (31600215) and the Yunnan Applied Basic Research Projects- General Program (2015FB171, 2017FB057).

Acknowledgments: This research was supported by grants from the National Natural Science Foundation of China (31600215) and the Yunnan Applied Basic Research Projects General Program (2015FB171, 2017FB057). The authors would like to thank Mary Roth for the acquisition and processing of the ESI-MS/MS data at the Kansas Lipidomics Research Center Analytical Laboratory.

Conflicts of Interest: The authors declare no conflicts of interest. 


\section{Abbreviations}

$\begin{array}{ll}\text { SCPL } & \text { serine carboxypeptidase-like } \\ \text { PG } & \text { phosphatidylglycerol } \\ \text { PC } & \text { phosphatidylcholine } \\ \text { PE } & \text { phosphatidylethanolamine } \\ \text { PI } & \text { phosphatidylinositol } \\ \text { PS } & \text { phosphatidylserine } \\ \text { PA } & \text { phosphatidic acid } \\ \text { MGDG } & \text { monogalactosyldiacylglycerol } \\ \text { DGDG } & \text { digalactosyldiacylglycerol } \\ \text { DBI } & \text { double bond index } \\ \text { ESI-MS/MS } & \text { electrospray ionization tandem mass spectrometry }\end{array}$

\section{References}

1. Feng, Y.; Xue, Q. The serine carboxypeptidase like gene family of rice (Oryza sativa L. ssp. japonica). Funct. Integr. Genom. 2006, 6, 14-24. [CrossRef] [PubMed]

2. Mugford, S.T.; Milkowski, C. Serine carboxypeptidase-like acyltransferases from plants. Methods Enzym. 2012, 516, 279-297.

3. Jiang, P.; Gao, J.; Mu, J.; Duan, L.; Gu, Y.; Han, S.; Chen, L.; Li, Y.; Yan, Y.; Li, X. Interaction between serine carboxypeptidase-like protein TtGS5 and Annexin D1 in developing seeds of Triticum timopheevi. Appl. Genet. 2020, 61, 151-162. [CrossRef] [PubMed]

4. Fraser, C.M.; Rider, L.W.; Chapple, C. An expression and bioinformatics analysis of the Arabidopsis serine carboxypeptidase-like gene family. Plant Physiol. 2005, 138, 1136-1148. [CrossRef] [PubMed]

5. Dal Degan, F.; Rocher, A.; Cameron-Mills, V.; von Wettstein, D. The expression of serine carboxypeptidases during maturation and germination of the barley grain. Proc. Natl. Acad. Sci. USA 1994, 91, 8209-8213. [CrossRef] [PubMed]

6. Bullock, T.L.; Breddam, K.; Remington, S.J. Peptide aldehyde complexes with wheat serine carboxypeptidase II: Implications for the catalytic mechanism and substrate specificity. J. Mol. Biol. 1996, 255, 714-725. [CrossRef] [PubMed]

7. Washio, K.; Ishikawa, K. Structure and expression during the germination of rice seeds of the gene for a carboxypeptidase. Plant Mol. Biol. 1992, 19, 631-640. [CrossRef]

8. Washio, K.; Ishikawa, K. Cloning and sequencing of the gene for type I carboxypeptidase in rice. Biochim. Biophys. Acta 1994, 1199, 311-314. [CrossRef]

9. Washio, K.; Ishikawa, K. Organ-specific and hormone-dependent expression of genes for serine carboxypeptidases during development and following germination of rice grains. Plant Physiol. 1994, 105, 1275-1280. [CrossRef]

10. Li, Z.; Tang, L.; Qiu, J.; Zhang, W.; Wang, Y.; Tong, X.; Wei, X.; Hou, Y.; Zhang, J. Serine carboxypeptidase 46 Regulates Grain Filling and Seed Germination in Rice (Oryza sativa L.). PLoS ONE 2016, 11, e0159737. [CrossRef]

11. Liu, H.; Wang, X.; Zhang, H.; Yang, Y.; Ge, X.; Song, F. A rice serine carboxypeptidase-like gene OsBISCPL1 is involved in regulation of defense responses against biotic and oxidative stress. Gene 2008, 420, 57-65. [CrossRef] [PubMed]

12. Li, A.X.; Steffens, J.C. An acyltransferase catalyzing the formation of diacylglucose is a serine carboxypeptidase-like protein. Proc. Natl. Acad. Sci. USA 2000, 97, 6902-6907. [CrossRef] [PubMed]

13. Moura, D.S.; Bergey, D.R.; Ryan, C.A. Characterization and localization of a wound-inducible type I serine-carboxypeptidase from leaves of tomato plants (Lycopersicon esculentum Mill.). Planta 2001, 212, 222-230. [CrossRef] [PubMed]

14. Mehta, R.A.; Mattoo, A.K. Isolation and identification of ripening-related tomato fruit carboxypeptidase. Plant Physiol 1996, 110, 875-882. [CrossRef]

15. Bienert, M.D.; Delannoy, M.; Navarre, C.; Boutry, M. NtSCP1 from tobacco is an extracellular serine carboxypeptidase III that has an impact on cell elongation. Plant Physiol 2012, 158, 1220-1229. [CrossRef] 
16. Cercos, M.; Urbez, C.; Carbonell, J. A serine carboxypeptidase gene (PsCP), expressed in early steps of reproductive and vegetative development in Pisum sativum, is induced by gibberellins. Plant Mol. Biol. 2003, 51, 165-174. [CrossRef]

17. Mugford, S.T.; Qi, X.; Bakht, S.; Hill, L.; Wegel, E.; Hughes, R.K.; Papadopoulou, K.; Melton, R.; Philo, M.; Sainsbury, F.; et al. A serine carboxypeptidase-like acyltransferase is required for synthesis of antimicrobial compounds and disease Resistance in oats. Plant Cell 2009, 21, 2473-2484. [CrossRef]

18. Li, J.; Lease, K.A.; Tax, F.E.; Walker, J.C. BRS1, a serine carboxypeptidase, regulates BRI1 signaling in Arabidopsis thaliana. Proc. Natl. Acad. Sci. USA 2001, 98, 5916-5921. [CrossRef]

19. Shirley, A.M.; McMichael, C.M.; Chapple, C. The sng2 mutant of Arabidopsis is defective in the gene encoding the serine carboxypeptidase-like protein sinapoylglucose: Choline sinapoyltransferase. Plant J. 2001, 28, 83-94. [CrossRef]

20. Shirley, A.M.; Chapple, C. Biochemical characterization of sinapoylglucose: Choline sinapoyltransferase, a serine carboxypeptidase-like protein that functions as an acyltransferase in plant secondary metabolism. J. Biol. Chem. 2003, 278, 19870-19877. [CrossRef]

21. Parzych, K.R.; Ariosa, A.; Mari, M.; Klionsky, D.J. A newly characterized vacuolar serine carboxypeptidase, Atg42/Ybr139w, is required for normal vacuole function and the terminal steps of autophagy in the yeast Saccharomyces cerevisiae. Mol. Biol. Cell 2018, 29, 1089-1099. [CrossRef] [PubMed]

22. Mugford, S.T.; Osbourn, A. Evolution of serine carboxypeptidase-like acyltransferases in the monocots. Plant Signal. Behav. 2010, 5, 193-195. [CrossRef] [PubMed]

23. Zhou, A.; Li, J. Arabidopsis BRS1 is a secreted and active serine carboxypeptidase. J. Biol Chem. 2005, 280, 35554-35561. [CrossRef] [PubMed]

24. Lehfeldt, C.; Shirley, A.M.; Meyer, K.; Ruegger, M.O.; Cusumano, J.C.; Viitanen, P.V.; Strack, D.; Chapple, C. Cloning of the SNG1 gene of Arabidopsis reveals a role for a serine carboxypeptidase-like protein as an acyltransferase in secondary metabolism. Plant Cell 2000, 12, 1295-1306. [CrossRef] [PubMed]

25. Ciarkowska, A.; Ostrowski, M.; Jakubowska, A. A serine carboxypeptidase-like acyltransferase catalyzes synthesis of indole-3-acetic (IAA) ester conjugate in rice (Oryza sativa). Plant Phys. Biochem. 2018, 125, 126-135. [CrossRef]

26. Fraser, C.M.; Thompson, M.G.; Shirley, A.M.; Ralph, J.; Schoenherr, J.A.; Sinlapadech, T.; Hall, M.C.; Chapple, C. Related Arabidopsis serine carboxypeptidase-Like sinapoylglucose acyltransferases display distinct but overlapping substrate Specificities. Plant Physiol. 2007, 144, 1986-1999. [CrossRef]

27. Stehle, F.; Brandt, W.; Schmidt, J.; Milkowski, C.; Strack, D. Activities of Arabidopsis sinapoylglucose: Malate sinapoyltransferase shed light on functional diversification of serine carboxypeptidase-like acyltransferases. Phytochemistry 2008, 69, 1826-1831. [CrossRef]

28. Stehle, F.; Stubbs, M.T.; Strack, D.; Milkowski, C. Heterologous expression of a serine carboxypeptidase-like acyltransferase and characterization of the kinetic mechanism. FEBS J. 2008, 275, 775-787. [CrossRef]

29. Dominguez, F.; Cejudo, F.J. Patterns of starchy endosperm acidification and protease gene expression in wheat grains following germination. Plant Physiol. 1999, 119, 81-88. [CrossRef]

30. Li, J.W.; Wang, X.M. Phospholipase D and phosphatidic acid in plant immunity. Plant Sci. 2019, $279,45-50$. [CrossRef]

31. Testerink, C.; Larsen, P.B.; van der Does, D.; van Himbergen, J.A.; Munnik, T. Phosphatidic acid binds to and inhibits the activity of Arabidopsis CTR1. J. Exp. Bot. 2007, 58, 3905-3914. [CrossRef] [PubMed]

32. Zhang, Q.; Lin, F.; Mao, T.; Nie, J.; Yan, M.; Yuan, M.; Zhang, W. Phosphatidic acid regulates microtubule organization by interacting with MAP65-1 in response to salt stress in Arabidopsis. Plant Cell 2012, 24, 4555-4576. [CrossRef] [PubMed]

33. Mao, X.; Liu, Q.; Qiu, Y.; Fan, X.; Han, Q.; Liu, Y.; Zhang, L.; Xue, C. Identification of a novel phospholipase $\mathrm{D}$ with high transphosphatidylation activity and its application in synthesis of phosphatidylserine and DHA-phosphatidylserine. J. Biotechnol. 2017, 249, 51-58. [CrossRef] [PubMed]

34. Roy Choudhury, S.; Pandey, S. Phosphatidic acid binding inhibits RGS1 activity to affect specific signaling pathways in Arabidopsis. Plant J. 2017, 90, 466-477. [CrossRef]

35. Munnik, T.; Arisz, S.A.; De Vrije, T.; Musgrave, A. G protein activation stimulates phospholipase D signaling in plant. Plant Cell 1995, 7, 2197-2210. [CrossRef]

36. Siloto, R.M.; Findlay, K.; Lopez-Villalobos, A.; Yeung, E.C.; Nykiforuk, C.L.; Moloney, M.M. The accumulation of oleosins determines the size of seed oilbodies in Arabidopsis. Plant Cell 2006, 18, 1961-1974. [CrossRef] 
37. Welti, R.; Li, W.; Li, M.; Sang, Y.; Biesiada, H.; Zhou, H.E.; Rajashekar, C.B.; Williams, T.D.; Wang, X. Profiling membrane lipids in plant stress responses. Role of phospholipase D alpha in freezing-induced lipid changes in Arabidopsis. J. Biol. Chem. 2002, 277, 31994-32002. [CrossRef]

38. Dormann, P.; Benning, C. Galactolipids rule in seed plants. Trends Plant Sci. 2002, 7, 112-118. [CrossRef]

39. Wang, G.; Ryu, S.; Wang, X. Plant phospholipases: An overview. Methods Mol. Biol. 2012, 861, $123-137$.

40. Guo, L.; Mishra, G.; Taylor, K.; Wang, X. Phosphatidic acid binds and stimulates Arabidopsis sphingosine kinases. J. Biol. Chem. 2011, 286, 13336-13345. [CrossRef]

41. Zhang, Q.; Qu, Y.; Wang, Q.; Song, P.; Wang, P.; Jia, Q.; Guo, J. Arabidopsis phospholipase D alpha 1-derived phosphatidic acid regulates microtubule organization and cell development under microtubule-interacting drugs treatment. J. Plant Res. 2017, 130, 193-202. [CrossRef] [PubMed]

42. Kim, S.C.; Guo, L.; Wang, X. Phosphatidic acid binds to cytosolic glyceraldehyde-3-phosphate dehydrogenase and promotes its cleavage in Arabidopsis. J. Biol. Chem. 2013, 288, 11834-11844. [CrossRef] [PubMed]

43. Chen, J.; Streb, J.W.; Maltby, K.M.; Kitchen, C.M.; Miano, J.M. Cloning of a novel retinoid-inducible serine carboxypeptidase from vascular smooth muscle cells. J. Biol. Chem. 2001, 276, 34175-34181. [CrossRef] [PubMed]

44. Granat, S.J.; Wilson, K.A.; Tan-Wilson, A.L. New serine carboxypeptidase in mung bean seedling cotyledons. J. Plant Physiol. 2003, 160, 1263-1266. [CrossRef]

45. Devaiah, S.P.; Roth, M.R.; Baughman, E.; Li, M.; Tamura, P.; Jeannotte, R.; Welti, R.; Wang, X. Quantitative profiling of polar glycerolipid species from organs of wild-type Arabidopsis and a PHOSPHOLIPASE D $\alpha 1$ knockout mutant. Phytochemistry 2006, 67, 1907-1924. [CrossRef]

46. Gut, H.; Matile, P. Breakdown of galactolipids in senescent barley leaves. Botanica Acta 1989, 102, 31-36. [CrossRef]

47. Yang, S.F.; Freer, S.; Benson, A.A. Transphosphatidylation by phospholipase D. J. Biol. Chem. 1967, 242, 477-484.

48. Baumert, A.; Milkowski, C.; Schmidt, J.; Nimtz, M.; Wray, V.; Strack, D. Formation of a complex pattern of sinapate esters in Brassica napus seeds, catalyzed by enzymes of a serine carboxypeptidase-like acyltransferase family? Phytochemistry 2005, 66, 1334-1345. [CrossRef]

49. Ciarkowska, A.; Ostrowski, M.; Jakubowska, A. Abiotic stress and phytohormones affect enzymic activity of 1-O-(indole-3-acetyl)- $\beta$-d-glucose: Myo-inositol indoleacetyl transferase from rice (Oryza sativa). J. Plant Phys. 2016, 205, 93-96. [CrossRef]

50. Gardiner, J.; Collings, D.A.; Harper, J.D.; Marc, J. The effects of the phospholipase D-antagonist 1-butanol on seedling development and microtubule organisation in Arabidopsis. Plant Cell Physiol. 2003, 44, 687-696. [CrossRef]

51. Motes, C.M.; Pechter, P.; Yoo, C.M.; Wang, Y.S.; Chapman, K.D.; Blancaflor, E.B. Differential effects of two phospholipase D inhibitors, 1-butanol and $\mathrm{N}$-acylethanolamine, on in vivo cytoskeletal organization and Arabidopsis seedling growth. Protoplasma 2005, 226, 109-123. [CrossRef] [PubMed]

52. Dhonukshe, P.; Laxalt, A.M.; Goedhart, J.; Gadella, T.W.J.; Munnik, T. Phospholipase D activation correlates with microtubule reorganization in living plant cells. Plant Cell 2003, 15, 2666-2679. [CrossRef]

53. Bonfig, K.; Schreiber, U.; Gabler, A.; Roitsch, T.; Berger, S. Infection with virulent and avirulent P. syringae strains differentially affects photosynthesis and sink metabolism in Arabidopsis leaves. Planta 2006, 225, 1-12. [CrossRef] [PubMed]

54. Jia, Y.; Tao, F.; Li, W. Lipid profiling demonstrates that suppressing Arabidopsis phospholipase D $\delta$ retards ABA-promoted leaf senescence by attenuating lipid degradation. PLoS ONE 2013, 8, e65687. [CrossRef] [PubMed]

55. Jia, Y.; Li, W. Phospholipase D antagonist 1-butanol inhibited the mobilization of triacylglycerol during seed germination in Arabidopsis. Plant Divers. 2018, 40, 292-298. [CrossRef]

56. Rawyler, A.; Pavelic, D.; Gianinazzi, C.; Oberson, J.; Braendle, R. Membrane lipid integrity relies on a threshold of ATP production rate in Potato cell cultures submitted to anoxia. Plant Physiol. 1999, 120, $293-300$. [CrossRef]

(C) 2020 by the authors. Licensee MDPI, Basel, Switzerland. This article is an open access article distributed under the terms and conditions of the Creative Commons Attribution (CC BY) license (http://creativecommons.org/licenses/by/4.0/). 